\title{
The astronomic theory of climatic changes of Milutin Milankovich
}

Note: Items in Episodes' Classic Paper series normally analyze a single paper of major importance in the history of geosciences. The present contribution examines the book in which Milankovich summed up his life work.

One of the few Serbian scientists of worldwide renown, Milutin Milankovich, was professor of applied mathematics at Belgrade University. He was born in 1879 in Dalj, near Osjek (today in Croatia). He studied construction engineering in Vienna, graduated in 1902 and gained his $\mathrm{PhD}$ in 1904. After a brief but successful engineering practice in Vienna, he moved to Belgrade University. During his thirty years of work there he produced: a mathematical theory of the Earth's climate (1920); his astronomic theory of climatic changes (1930,1938, 1938a); and his theory of the secular wandering of the Earth's poles (1933). He retired in 1955 and died in Belgrade in 1958. He was a member of the Serbian Academy of Sciences and Arts and of several other academies. His autobiography has been published in English (Milanković, 1995), and a complete bibliography of his works is also available (Mužijeviić, 1979). According to NASA experts, Milankovich was one of the world's fifteen most important geoscientists.

At Belgrade University, Milankovich decided to use exact mathematical/astronomical methods to solve a difficult and important problem: the causes of Ice Ages. He knew his mathematics well, along with celestial mechan-

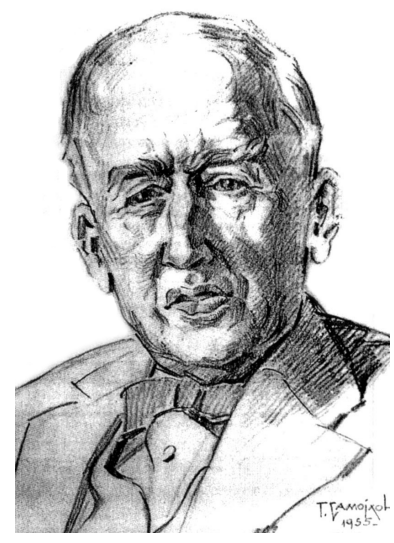

Figure 1 Milutin Milankovich ics and theoretical physics, and he was convinced that "it was possible to obtain a clear, scientifically explained and mathematically precise picture of the secular variations of the distribution of solar radiation on the Earth's surface". From that first idea in 1911 there followed decades of systematic, fundamental, and thorough work. What was amazing in his work was that he knew what needed to be done and how it should be done; and in particular he had the conviction that he was able to do it.

Milankovich was naturally well aware of earlier attempts to apply astronomical methods to account for Ice Ages (Milankovich, 1920). In "The Canon", he specially mentioned the pioneering work of Joseph-Alphonse Adhémar and James Croll (Milanković, 1998, pp. 499-502). However, he concluded that:

All of these theories have ... the same fault. None of them have correctly taken into account the variability of all the astronomical elements that affect the irradiation of the Earth. ... Besides, none of these theories was able to tackle mathematically the decisive influence of variations in the obliquity of the ecliptic on the irradiation of the Earth (Milankovic, 1998, p. 506).

Milankovich published the results of his work in about thirty publications, as he completed them (Milanković,1995). Then finally, in 1941, he synthesised all his results in his magnum opus: Kanon der Erdbestrahlung und seine Anwendung auf das Eiszeitproblem"The Canon".

\section{The Canon of insolation}

The original edition of "The Canon" was published in German (Milankovich, 1941). It was translated into Serbian (Milankovi'c, 1997), into English in Jerusalem (Milankovich, 1969), and finally into English again in Belgrade (Milankovi'c , 1998). The present review is based on the Belgrade translation (Milankovi'c , 1998), edited by the Textbook Publishing Company, Belgrade. The book has 634 pages, 57 illustrations, 28 tables, and 1338 equations. This paper seeks to give a general overview of Milankovich's accomplishments. The account does not follow the historical order of his discoveries, but the order as they appear in "The Canon". The translations quoted in this paper are from the English edition of 1998 (Milanković, 1998).

"The Canon" was an interdisciplinary work, between mathematics, astronomy, geophysics, and geology. With astronomical methods, Milankovich solved the problems of the secular perturbations in the movements of the Earth; with geophysical methods he solved the law of the Earth's insolation; while with geological methods he studied the succession and the history of Quaternary glaciations.

An individual present-day scientist, generally very specialised, will be unlikely to follow and understand all that was written in Milankovich's monograph. Fortunately, however, this is not really necessary for many readers. Numerous things were included in the book only because the author wanted to ensure that everything was confirmed and proved mathematically. Readers of "The Canon" should look for what is interesting to them. This review is intended mostly for geologists and geomorphologists.

This monograph comprises a Preface and six chapters. About them, the author wrote:

The first three parts of this work deal with the consequences of Newton's law of gravitation, and the theories of spherical astronomy, both important for my research. The other three parts deal with the conclusions drawn from the law of irradiation [i.e. they] apply this Canon to the Ice Age Problem ... This division gives an explicit expression of the basic idea of my entire research (pp. 61-62).

For the purposes of the present review, the most important material occurs in Chapters 4 and 6. The first three chapters are concerned with the interests of astronomers and also geophysicists. The reader should not be deterred by the parts of this review where particular equations or tables from "The Canon" are mentioned. The purpose of mentioning them is to help those who have the book in front of them and want to have more detailed information about certain solutions, results, and proofs.

In his proofs, Milankovich used only the basic tools of spherical astronomy, rational mechanics, theoretical physics, and mathematics, making use of vector analysis. But he knew that many naturalists from the descriptive sciences would not be able to follow his explanations in "The Canon" strictly based on mathematical procedures; and large portions of the book were not intended for such readers but for astronomers and geophysicists. At the same time, he was aware that in the future it would be descriptive naturalists who would investigate the consequences of the climatic changes in the field. For that reason, he later published a short text about the essence of the astronomical theory of climatic changes, which is comprehensible for every investigator (Milankovich, 1953). 


\section{Introduction}

In the Introduction to "The Canon" Milankovich explained why he approached the problem of the origins of the Ice Ages, and he described chronologically the way in which he solved it. This part of the book is important to every reader who wants to understand any part of "The Canon". Many segments of the Introduction are referred to in various places in the present review.

\section{PART 1}

The planets' motions around the Sun and their mutual perturbations

Under this heading, Milankovich, in a simple but original manner, first deduced Newton's law of gravitation from Kepler's laws (Newton's own geometrical procedure had been excessively complicated). Then Milankovich treated the two-body and the many-body problems of celestial mechanics and established the perturbation theory for astronomy. For this, he used five geometrical constructions and 304 equations. At the end of the chapter, Milankovich concluded that the calculations showed that:

the orbital eccentricities and inclinations of all the major planets oscillate within narrow limits. This, together with the secular invariability of the semi-major axes of the planets' orbits, appears to warrant the stability of our planetary system for an immeasurably long time (p. 153).

\section{PART 2}

\section{The Earth's rotation}

This chapter contains the classical theory of the Earth's rotation, simplified by the introduction of vector methods for dealing with the general equations of that theory. Also, it considered the application of these equations to diurnal rotation, precession, and the nutation of the Earth's axis. The deductions were performed with the aid of 311 equations.

In a special addendum to Chapter 2, there was a short discussion of the "measuring and reckoning of time". In fact, there was a suggestion for a new calendar (the so-called "Milankovich Calendar"), which is more precise than Julian one.

\section{PART 3}

\section{Secular wanderings of the Earth's polar axis}

In this chapter, Milankovich presented his original concept of the secular wanderings of the Earth's rotational axis. This was accomplished by means of 169 equations and three numerical tables (II, III, and IV).

According to Milankovich, the continental blocks sink into their underlying "fluidal" base, and slide around, 'aiming to achieve' isostatic equilibrium. In his conclusion about this problem, he wrote:

For an extraterrestrial observer, the displacement of the pole take place in such a way that the ... Earth's axis maintains its orientation in space, but the Earth's crust is displaced on its substratum so that the North Pole of the Earth describes the curve on the Earth's surface illustrated in Figure 32 (p. 315).

This process not only moves the existing system of climatic zones over the Earth's surface but also "may have an influence" on the climate.

\section{PART 4}

\section{The Earth's insolation and its secular changes}

The first part of this chapter provided the best available knowledge of the present state of the Earth's insolation: the solar constant, the law of insolation, the diurnal and annual march of insolation*, the astronomical seasons of the year, etc. The numerical data in this chapter were needed for the further development of the theory.

In the second part of this chapter Milankovich gave the results of his investigations of the secular variation of the astronomical elements that determine the conditions of the Earth's insolation. First (1) the astronomic elements were defined; (2) then their secular variations were determined, calculated, and presented numerically (Table VIII); and (3) the secular changes in the Earth's insolation were analytically explained using the concept of "caloric half-years" (i.e., the solar radiation falling on one of the Earth's hemispheres during half a year). All this was explained with 227 equations, nine tables (V-XIV) and eight geometrical constructions.

In this section of "The Canon", the crucial part of the Milankovich's theory was explained and must therefore be treated in more detail here. This is what the author wrote about it:

\section{(1) Astronomical elements}

In Figure 40 [see Fig. 2], point S represents the centre of the Sun, and the ellipse PIAIIIP represents the Earth's annual orbit round the Sun. Let us draw through S a line SV, normal to the Earth's orbital plane, and directed to the north another line SN parallel to the rotational axis of the Earth; then the angle VSN represents the inclination of the rotational axis of the Earth or the obliquity $\varepsilon$ of the ecliptic. The plane E, defined by the straight lines $S V$ and $S N$, is normal to the Earth's orbital plane and intersects it along the straight line II-IV. The points II and IV represent, as can easily be seen, the solstices on the Earth's orbit, and if in the orbital plane we draw a straight line through S, normal to II-IV this will intersect the orbit at the points I and III, which represent the Earth's two equinoxes. The time intervals between the four cardinal points I, II, III, IV through which the Earth passes represent the astronomical annual seasons; the orbital interval I, II, III corresponds to the northern summer half-year Ts and the interval III, IV, I to the northern winter half-year Tw. The inequality of the sections I, II, III and III, IV, I implies the inequality of these halfyears... (p. 357).

The position of these four points on the Earth's orbit is determined by the angle IIISP . . which may be called $\Pi \gamma$ and represents the longitude of the perihelion $[P]$ [relative] to the vernal point, because at the time of vernal equinox the Sun appears to be projected on the celestial sphere in the direction IS (p. 357).

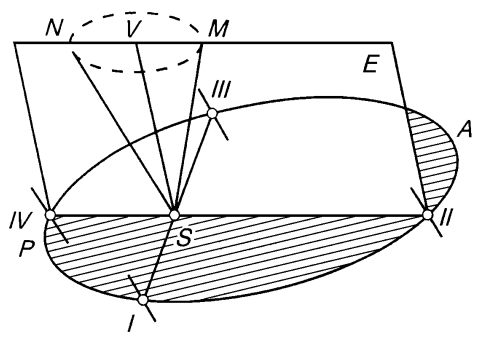

Figure 2 Milankovich's Figure 40 (explanation in text).

The third astronomical element influencing the irradiation is the secular change of the eccentricity $(e)$ of the Earth's elliptical orbit.

Following this analysis, Milankovich proved that only three astronomical elements are important for calculations of the secular changes of the Earth's insolation: $\prod \gamma, e$, and $\varepsilon$ (p. 359).

* The English translaton of "The Canon" (1998) uses the rather infelicitous word 'march'. One might also use 'course' or 'progress'. However, the precedent of using the word 'march' has been followed here. 
(2) The secular variability of the astronomical elements

The author further wrote:

If the planets did not disturb one another in their course and if the Earth's axis of rotation kept its orientation in space, then the Earth's orbit (Figure 40) would be unchanging and its cardinal points I, II, III, and IV would be fixed. The annual march of the insolation of the Earth ... would recur without change year after year. This, however, is not the case. The precession of the Earth's axis of rotation . . . if it alone were active, would displace $S N$ drawn parallel to it [i.e., the rotational axis] in such a way that in about 26,000 years it would describe the circular cone NSM. The axis of this cone is SV, [and] its vertex [has the] angle e. Owing to this rotation of the Earth's axis, the plane E turns around the straight line SV as axis, and the cardinal points I, II, III, IV move clockwise along [or round] the Earth's orbit. They would accomplish a complete revolution along this orbit in 26,000 years if this orbit were fixed. However, due to the mutual perturbation of the planets, the major axis of the orbital ellipse [also] moves toward the cardinal points, and therefore these points perform a full revolution (from perihelion to perihelion) in about 22,000 years. During this time-span, which can be considered only as an average value, $\Pi \gamma$ increases by $360^{\circ}$ (pp. 357-358).

Owing to the perturbations, the Earth's orbit gradually changes its shape; although its major semi-axis remains unchanged, and the eccentricity e undergoes significant secular changes (p. 358).

The average period of these oscillations is 92,000 years (but the individual periods vary between 77,000 and 103,000 years; p. 386).

The plane of the orbit also varies, ... which determines its position in space... [thereby] affecting the obliquity $\varepsilon$ of the Earth's axis of rotation, SN. A further consequence of the variation of the orbital plane is the fact that $S V$, which we have hitherto supposed to be fixed, gradually changes its orientation in space, whereby the cone NSM loses its immobility and regularity (p. 358). The interval between two consecutive maxima is about 40,000 years (p. 384).

In brief, according to Milankovich, among the three basic astronomic elements $(\Pi \gamma, e$, and $\varepsilon$ ) each has its own periodical cycle of changes: (Berger et al., 1984) due to precession-22,000 years; (Berger et al., 2005) due to changes in the orbital eccentricityabout 92,000 years; and (De Boer and Smith, 1994) due to changes in the obliquity of the ecliptic-41,000 years. Each of these cycles occurs independently of the other two. Sometimes their influence on the amount of heat received by certain parts of the Earth nullifies each other. Sometimes the changes increase or decrease the quantity of the heat. In the later case, with the decrease of irradiation at the various latitudes of the northern hemisphere, glaciation and an Ice Age occur.

Milankovich concluded that:

These variations of the astronomical elements can be formulated with mathematical exactness by using the theories of celestial mechanics [see Part 2], and can be followed, step by step, through long intervals both in the past and into the future (p. 358).

At the time of Milankovich's work, only two "suitable computations" of the secular variations of the elements of the Earth's orbit were available in the literature (p. 369). They were the work of the Frenchman Urbain Leverrier and the American John Stockwell; but unfortunately "despite the work of these two astronomers, not all the work has been accomplished to prepare an approach to the computation of the secular march of Earth's insolation" (p. 369). Conse- quently, Milankovich found it necessary to make new calculations based on Leverrier's work (p. 371).

Milankovich went into precise and detailed calculations of the three astronomical elements for the last 600,000 years. He accepted but corrected the Leverrier and Stockwell computation by using newer and more accurate values for the masses of the planets in the solar system. That was a substantial mathematical task, which the interested reader can find in "The Canon" (pp. 362-375). As a result, Table VIII, "Secular variations of the elements $\Pi \gamma, e$, and $\varepsilon$ according to Stockwell-Pilgrim" (pp. 364-368); and Table IX "Secular variations of the elements $\Delta \varepsilon=\varepsilon-\varepsilon_{0}: \Delta(e \sin \Pi \gamma)=e \sin \prod \gamma-e_{0}$ sin $\Pi \gamma^{\circ}$ according to Leverrier-Mišković" (pp. 372-374), were created. The second table was especially important for the further calculations but it is too large for reproduction here.

\section{(3) Secular march of the Earth's irradiation}

Approaching the computation of the secular variations of the Earth's irradiation, Milankovich introduced three important innovations. First, he discovered that the changes of all three astronomical elements $\left(\prod \gamma, e\right.$, and $\varepsilon$ ) should be taken into account simultaneously, which had not been understood by his predecessors (p. 506). Second, he expressed "the insolation in question in 'canonic units"' (p. 379). And third, he introduced the notion of "caloric half-years" (p. 390).

Treating the secular changes of the Earth's irradiation generally, Milankovich particularly insisted on the importance of the calculation of the variations of the radiation received during the astronomical half-years resulting from an increase in the obliquity of the ecliptic by one degree. This was shown in the very important Table XII (p. 383).

"Canonic units", wrote Milankovich

are the units which we obtain if we take the solar constant as the unit of radiation and a hundred thousandth part of the year as the time unit):

$$
J_{0}=1 \quad T=100,000
$$

If we introduce these values ... [in the computation,] we obtain the radiation received during the astronomical half-years $T_{s}, T_{w}$ and during the whole year (see Table XI) (p. 379).

However,

[t]he difference between the astronomical summer and winter half-year at present amounts to 7 days and 14 hours. This difference can reach \pm 31 days and 20 hours due to the variability of astronomical elements (pp. 389-390).

It follows that the astronomical half-years $T_{s}$ and $T_{w}$ do not divide the year into an interval of stronger irradiation and another one of weaker irradiation, because as the aforementioned examples show, the irradiation in the final interval of the summer half-year is smaller than that at the end of the winter half-year. . . . This is the reason why the astronomical seasons cannot provide a better insight into the march of insolation in distant times (p. 390).

For this reason, but also to simplify his calculations, Milankovich divided

the year into two equally long, and consequently, real half-years, one of which comprise [d] all those days of the year during which the irradiation at the latitude in question is stronger than on any day of the other half-year (p. 390).

These two intervals he called the "caloric summer half-year" and the "caloric winter half-year" ( $\mathrm{W}_{\mathrm{s}}$ and $\mathrm{W}_{\mathrm{w}}$; p. 390).

The caloric half-years will always have ... the same duration of 182 days, 14 hours and 54 minutes. 
So, according to Milankovich, they furnished:

an instrument by which we can precisely follow the secular march of insolation (p. 390).

[This instrument] also enables us to tackle mathematically the most important effect of this march, the secular displacement of the snow line (p. 391).

In the chapter titled "Analytical description of the secular march of the Earth's irradiation" (pp. 377-411), Milankovich completed his mathematical apparatus (with caloric seasons included, $\mathrm{p}$. 544) "necessary for the computation of the secular variations of the insolation and complemented for further use by Tables IX, XII and $X I V$ " (p. 509). (Readers who want to follow the author's explanations mathematically should consult this chapter). Here he established equations by means of which the irradiation for the Northern Hemisphere could be calculated (p. 402):

$$
\begin{aligned}
\Delta \mathrm{Q}_{\mathrm{s}} & =\Delta \mathrm{W}_{\mathrm{s}} \Delta \varepsilon-m \Delta\left(e \sin \prod \gamma\right) \\
\Delta \mathrm{Q}_{\mathrm{w}} & =\Delta \mathrm{W}_{\mathrm{w}} \Delta \varepsilon+m \Delta\left(e \sin \prod \gamma\right)
\end{aligned}
$$

There were similar equations for the southern hemisphere (188) but with opposite signs (+ and - ).

In the above, $\Delta \mathrm{Q}_{\mathrm{s}}$ and $\Delta \mathrm{Q}_{\mathrm{w}}$ denote summer and winter caloric half-years for a certain year. The expressions $\Delta \mathrm{W}_{\mathrm{s}}$ and $\Delta \mathrm{W}_{\mathrm{w}}$ are the changes of irradiation at a certain latitude for summer and winter " $a t$ the present" if the inclination of the ecliptic is increased by one degree. (About the notion of 'the present', Milankovich wrote: "Tables XI, XII, and XIII, based on $e=0.0168$ and $\varepsilon=23^{\circ} 27^{\prime} 30^{\prime}$ ", can be considered valid for many years, which I will in general call 'the present' ", pp. 400-401). $\Delta \varepsilon$ denoted the change of the inclination of the ecliptic from its present value; $e$ denoted eccentricity of the ecliptic in the given year; П $\gamma$ was the perihelion related to the vernal equinoctial point (I in Fig. 2); and $m$ was the coefficient ( $\varphi$ for certain geographic latitudes, as calculated by means of Equation 169) for that period.

The numerical values of $\mathrm{W}_{\mathrm{s}}$ and $\mathrm{W}_{\mathrm{w}}$ in (187) and (188) could be taken from Table XII; those of $\Delta \varepsilon$ and $\Delta\left(e \sin \prod \gamma\right)$ from Table IX; and values of $m$ from Table XIV.

Tables IX, XII, and XIV contain all the data necessary to compute by means of (187) and (188) the secular march of irradiation received by individual latitudes for the past six hundred thousand years (p. 402).

The aforementioned equations summed up the whole mathematical apparatus of Milankovic's calculations of astronomical and insolation changes. This was why they also appeared later in the monograph and were the starting-point equations for all further calculations in Part 6 of the book (1 and 2, pp. 509-510).

\section{PART 5}

The connection between insolation and the Earth's temperature and atmosphere. The mathematical theory of the Earth's climate

In this chapter (pp. 415-493), all the contents were included. It was about the principles of the mathematical theory of climate and its use or application. In the introduction, the basic facts and physical laws of the atmosphere, and its 'junction' with the soil were explained. Then the connection between irradiation and temperature was described: (a) under conditions of steady insolation; and (b) in the case of variable radiation. The proof was derived using 227 equations, ten tables (V-XIV), and eight figures.

\section{PART 6}

\section{The Ice Age, its mechanism, structure, and chronology}

In the Introduction to this chapter, Milankovich defined the Ice Age and described how it was discovered. Then he briefly demonstrated "the historically most interesting theories, which tried to explain the theories of the Ice Ages by astronomical causes, and which [we]re for this reason known as the astronomical theories of the Ice Ages" (p. 499).

In the last chapter of "The Canon", which was the largest (pp. 497-619), Milankovich used all that had been mathematically proven in the earlier parts of the monograph. The numerical paleoclimatological tables for certain latitudes (Tables XXV and XXVIII), and insolation curves (p. 545) were of special significance however.

Starting from the equations for the estimation of the irradiation of the caloric half-years (187 and 188, p. 402-which are the same as Equations 1 and 2 in Part 6, pp. 509-510) Milankovich calculated the secular march of insolation during the past 600,000 years. Initially, this was done for latitudes $55^{\circ}, 60^{\circ}$, and $65^{\circ}$. Subsequently, he made calculations for latitudes $5^{\circ}, 15^{\circ}, 25^{\circ}, 35^{\circ}, 45^{\circ}, 55^{\circ}, 65^{\circ}$, and $75^{\circ}$, both for the northern and southern hemispheres. The quantities of heat supplied at individual latitudes by radiation during the caloric half-years were presented in canonic units in Table XXV (pp. 513-540). This table, which contained 5,600 numbers, "mathematically represent [ed] the history of insolation for the past 600 millennia-a so called Canon of insolation" (p. 512). So "with this canon one could attempt to study the phenomenon of the Ice Ages" (p. 543).

While Milankovich was preparing to present the march of insolation, both numerically and graphically, for the higher northern latitudes during the past 650,000 years, he became aware-from the famous German climatologist Wladimir Köppen (Alfred Wegener's father-in-law) - that:

it is the low summer temperature that produce glaciation. A large number of cold summers must be the cause of glaciation and they are to be considered responsible for the formation of inland-ice (p. 544).

That was most important for Milankovich and directed his attention to the significance of periods with cold summers, rather than cold winters.

\section{Radiation curve}

Bearing in mind Köppen's suggestion, Milankovich started on his calculations. About these and about the results of the calculations he wrote:

My computations dealt with the summer heat supplied to the northern latitudes at $55^{\circ}, 60^{\circ}$ and $65^{\circ}$ during the period of time [of 600,000 years backwards from the year 1800] .... I used the numerical values of the secular variations of the astronomical elements given in Table VIII and computed by [the astronomer Ludwig] Pilgrim. Having thus computed the desired radiative variations, I transformed these changes, with Köppen's approval, into hypothetical latitudinal oscillations, because I wanted to obtain a geometrical picture of these variations.

I thus obtained three zig-zag lines, later called "radiation curves", which were drawn on a graph and added to the Köppen-Wegener publication as a separate table.

The upper graph in Figure 48 is the one referring to the latitude of $65^{\circ} \ldots$. The zig-zag lines referring to $55^{\circ}$ and $60^{\circ}$ are not reproduced in Figure 48, since they are nearly parallel to that for $65^{\circ}$.

If we examine the upper graph in Figure 48, we can see nine particularly sharp drops in the summer radiations, which occurred in the 589th, 548th, 475th, 434th, 231st, 187th, 116th, $72 n d$ and 22nd millennia [before the year 1800]. These nine incursions of cold appear in four groups . . . Köppen recognized in these four groups the four Ice Periods of the Penck-Brïckner scheme (pp. 544-546). 


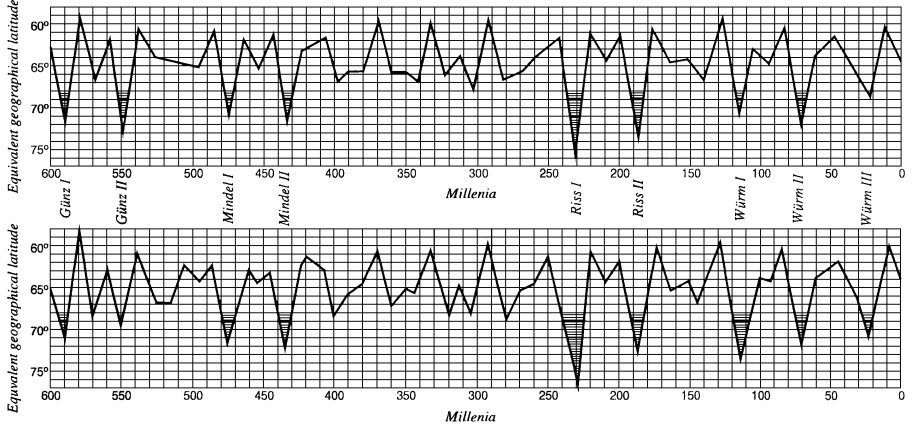

Figure 3 Amplitudes of the secular variations of the summer radiation at the northern latitude of $65^{\circ}$ : above-the old graph, computed from the data of Table VIII; below-the new graph, computed from the data of Table IX (Milankovich, Figure 48).

Thus it seemed that it was already possible to make a crude glacial curve, almost identical to the scheme of four Pleistocene glaciations (Günz, Mindel, Riss, and Würm) of Albrecht Penck and Eduard Brückner, based upon studies of gravels in river terraces in valleys running northward from the European Alps. The significant difference lay in the fact that Milankovich's curve had a precise time calibration, expressed in thousands of years. It superseded the crude schematization of Penck and Brückner, and gave it an explanation as well as increased precision. It is important to note that soon after its publication in 1924 (as a table in a volume by Köppen and Wegener: Die Klimate der geologischen Vorzeit), Milankovich's insolation curve was accepted by many investigators as a preliminary Ice Age calendar, which made possible the absolute dating of glacial epochs.

\section{Glacial curve}

Milankovich stressed that:

Köppen, with his ingenious insight, was the first to discover the connection between the secular march of insolation explored mathematically and the proved historical climates of the Earth (p. 547).

Then Milankovich used thirteen pages to describe results from many researchers who confirmed the similarity of the insolation curve to the data about glacial traces as observed in the field (in the northern and central Europe and in the Alps). Among others, the works of Wolfgang Soergel and Barthel Eberl were especially important.

Milankovich also wrote that his

most important result concerned the question of whether the influence of the variability of the astronomical elements (which could now be calculated uniquely) on the march of insolation was sufficient to fully explain the largest climatic fluctuations of the Quaternary. Some scientists doubted this. It was therefore desirable to complete my calculations on the secular march of insolation by determining climatic effects of this march, thus seeing the largeness of these effects (p. 58).

In order to solve the question posed, Milankovich began " $b y$ analyzing mathematically the connection between the altitude of the snow line and the radiant energy corresponding to the caloric summer half-year" (p. 58). Comparing the snow-limit curve and the summer insolation (p. 569), he found that their correlation coefficient was extraordinary high $(\mathrm{k}=0.996)$. This was a

mathematical proof of the deep connection between the altitude of the snow limit at different latitudes and the corresponding insolations of the caloric summer half-year (p. 570). that:

Among other things during his calculations, Milankovich found

it is clear that to any change of the summer heat by one canonic radiation unit, there corresponds a displacement of the snow limit of 1.09 or 1.00 metres (p. 572).

The direction of this movement was introduced in Table XXV, in which he placed a plus sign $(+)$ in front of the canon unit values for an upward displacement of the snow line and a minus sign (-) for downward displacement. Thus the tables had "tangible climatological importance" (p. 58).

In this connection, Milankovich (not without criticism) wrote:

The tables of the Earth's insolation thus show that the displacements of the snow line, caused directly by the change of this insolation, were powerful enough to leave clear traces of the march of secular insolation on the Earth's face, but not sufficient to cause the great glaciations of prehistoric times to their full extent. For this, an additional climatic factor was necessary (p. 58).

Looking for those additional climatic factors, Milankovich found that it was the albedo or

the reflective capacity of these snow-white polar caps, [which is very high because] they reflected into space a considerable part of the heat received through insolation. This quantity of heat was therefore lost to the heat budget of the Earth (p. 58).

For the calculation of this influence, however, data obtained by the systematic investigations of the snow-covered regions of the Earth were also needed (p. 59).

Luckily, at the same time as Milankovich's work a young French meteorologist, Joseph Devaux, published data "on the reflective power of snow covers which he had obtained on the glaciers of the Pyrenees, the Alps, and in Greenland" (p. 59). Based on Devaux's data, Milankovich calculated the secular course of insolation, taking into account the reflective power of the Earth's globe in canonic units for the northern and southern ice-caps reaching to the 55th parallels (pp. 574-580). The results were given in his Table XXVIII (pp. 581-601) and the accompanying discussion. Based on the complete analysis, Milankovich found that the calculated effects:

indicated that the march of Earth's insolation in distant times, calculated by taking into consideration the varying reflective power of the Earth, was quite sufficient to fully explain even the largest changes in the Quaternary (p. 59).

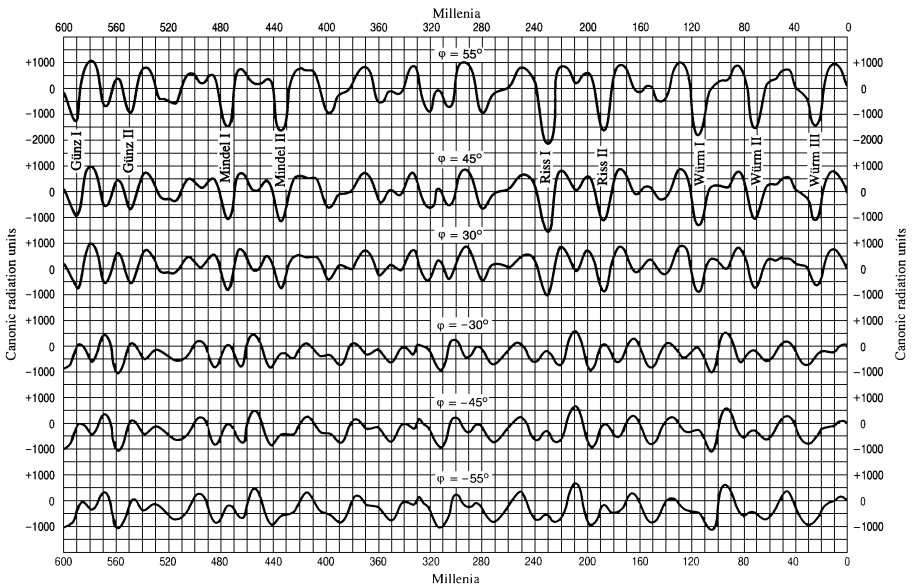

Figure 4 The Earth's secular march of insolation, taking into account the variations in reflective power (Milankovich, Figure 56). 
Milankovich concluded:

The cooling activity of the temporarily enlarged ice-caps of the Earth, becomes a secondary effect of the secular march of Earth's insolation, since it is produced by this march. Therefore, the new radiation curves, determined by taking this effect into consideration [Fig. 56], have the same pattern as those computed earlier [Fig. 55]-differing only in their greater amplitudes (p. 59) . . . but they are numerically distinguished by the inclusion of the climatic effects of this cause (p. 611).

So, satisfied, Milankovich added:

My calendar of the Glacial Period is thus still valid (p. 59).

\section{Final remarks}

Milankovich ended his book with a chapter on the mechanism and march of the great climatic oscillations of the Quaternary (pp. 603-619). In it, he described and compared a number of insolation curves, with and without consideration of the influence of the reflective power of the snow cover (Figures 55 and 56), and found that they agreed with the data compiled in his Tables XXV and XXVIII.

He specially showed the different numerical data for "the radiation curve of the secular march per unit surface area on the northern ice-cap down to $45^{\circ}$, taking into account the reflective power of the Earth" (p. 609). The second of the curves was shown in his Figure 56.

The course of this curve shows clearly that during the last 600,000 years the deficits of the summer radiation per unit surface are taken to be 1,000 canonic units [occurring] 7 times, 950 units once, and 700 units once. These nine [deficits] were the greatest variations during this period.

Table XXVIII gives information on the precise magnitude of these variation and their consequences. It can be seen that the maximum values occurred at the following points of time (in millennia before the year 1800):

$$
\begin{array}{lllllllll}
590.3 & 550 & 475.6 & 435 & 230 & 187.5 & 115 & 71.9 & 25
\end{array}
$$

At these times the downward displacement of the mean snow limit reached (in metres):

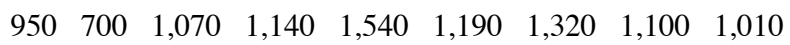

From Equation 16, the decrease in the mean temperature (in degrees centigrade) produced by the deficits in the summer radiation have been calculated:

$$
\begin{array}{lllllllll}
6.3 & 4.7 & 7.1 & 7.6 & 10.3 & 7.9 & 8.8 & 7.3 & 6.7
\end{array}
$$

From Equation 17 the mean annual temperature also decreased [for each major period of cooling] by at least

$$
\begin{array}{lllllllll}
2.2 & 1.5 & 2.5 & 3.1 & 4.0 & 2.8 & 3.3 & 2.8 & 3.0
\end{array}
$$

Consequently, these were periods with not only very cold summer half-years, but also when the entire year was cold.

These nine periods with the lowest descent of the snow limit [we]re not equally distributed over the last 600 millennia, but appear[ed] to [have been] arranged into four groups, the first three of which [we]re each composed of two, and the fourth of three cold incursions. These [we]re those groups in which Köppen recognized the four Glacial Periods of the Penck-Brïckner scheme in my first radiation curves (p. 610).

After this great achievement, Milankovich concluded:

The main results of this work were obtained, as its basic programmatic idea demanded, from Newton's law of gravitation and from the law of irradiation, without taking recourse to any hypothesis (p. 61).
Then, with satisfaction, he completed his book with the following words:

These causes-the changes in insolation brought about by the mutual perturbations of the planets-lie far beyond the vision of the descriptive natural sciences. It was therefore the task of the exact natural sciences to outline the above-mentioned scheme, by means of its laws ruling the universe and by its developed mathematical means (p. 619) . . By these applications, my work, based upon exact science [was finished and] passes into the sphere of the descriptive natural sciences. . . It is the hitherto missing link between celestial mechanics and geology (p. 62).

$* * *$

Finalizing his work, Milankovich emphasized that what he had done was only the first half of the task. Preliminary geological data from the field were found to agree with his insolation curves, but long and hard investigative work was still to be done. To accomplish that work, it has been necessary to investigate the connection between the mathematical insolation curves and geological evidence. Those investigations started while Milankovich was still alive but unfortunately he never saw even the first results. The important supporting data from the drilling investigations of the ocean floor came after his death.

The very expensive project CLIMAP (Climate, Langrage Investigation, Mapping and Predication), which was started in 1971, was especially important. Based on detailed multidisciplinary studies of undisturbed sediments from the bottom of the Indian Ocean, and their fossil contents, James Hays, John Imbrie, and Nicholas Shackleton, in their famous paper (Hays et al., 1976), concluded decisively that the movements of the ice-cap boundaries during the last several hundreds of thousands of years were influenced in accordance with three of Milankovich's astronomic cycles. In other words, the "changes in the geometry of the Earth's orbit [we]re the main reasons for the repeated changes during the Ice Ages."

The collection of new evidences has continued and has been published in special books (e.g., Berger et al., 1984; Imbrie, 1979) and at scientific conferences dedicated to Milankovich and his astronomical theory of climate changes. The first was held in Belgrade in 1979 (Garašanin, 1979), but an especially important meeting was the one held at Columbia University in 1982 (Berger et al., 1984). For the latter, authors from all over the world presented rich and diverse materials, all in accordance with Milankovich's theory. Recently, there has been a meeting in Belgrade under the title "Paleoclimate and the Earth Climate System", on the occasion of Milankovich's 125th anniversary (Berger et al., 2005).

Milankovich's climatic cycles are used today in many sciences. In geology, aside from the history of the Pleistocene, they are treated more generally in the discipline of cyclostratigraphy (Schwarzacher 1993; House and Gale, 1996). Astronomical cycles, thought to have been the cause of sedimentary cycles (EUG, 1989; De Boer and Smith, 1994) in the Carboniferous, Triassic, Jurassic, and Cretaceous (Hinnov, 2004), are evident, exactly as predicted by Milankovich (p. 615). And, from 1972, insolation curves have been calculated forwards into the future.

Investigations in the closing decades of the twentieth century have shown that there are other influences on the Earth's climate besides direct astronomical causes. For example, the amount of carbon dioxide in the atmosphere is presently increasing and there are cyclic changes in the intensity of solar radiation. This, however, cannot change the basic fact that "The Canon" will remain the foundation stone of climatology. The same goes for the interpretation of climatic changes through the whole geological history of the Earth.

The number of international recognitions Milankovich received for his work bears witness to his accomplishment and influence. There are craters on the Moon and Mars named after him, and also a planetoid. In 1993, the European Geophysical Society established a "Milutin Milankovich Medal", for successes in climatological investigations. He is also often called "the Founder of Cosmic Climatology" (Petrovic, 2004, in Berger et al., 2005).

During his lifetime, Milankovich worked in other fields too. But his other accomplishments were overshadowed by the great success of his astronomical theory of climatic changes. 


\section{Acknowledgments}

The writer of this article wishes to express his thanks to his son Goran Grubic and to David Oldroyd for their help in preparing this complex manuscript. Without their contributions, the result would undoubtedly be much less satisfactory. I am also indebted to the publisher of Milankovich's works - the Textbook Publishing Company (Zavod za udžbenike i nastavna sredstva), Belgrade-for their support and appreciation of the importance of the painstaking task.

\section{References}

Berger, A., Imbrie, I., Hays, I., Kukla, G., and Soltzman, B. (eds), 1984 Milankovich and Climate: Dordrecht, D. Reidel Publishing Co.

Berger, A., Ercegovac, M. and Mesinger, F. (eds), 2005, Paleoclimate and the Earth climate system, Milutin Milankovich Anniversary Symposium: Scientific Meetings, Serbian Academy of Sciences and Arts, v. 110 (Book 4): Belgrade, Serbian Academy of Sciences and Arts, Department of Mathematics, Physics and Geosciences.

De Boer, P. L. and Smith, D. G. (eds), 1994, Orbital forcing and cyclic sequences: International Association of Sedimentologists, Special Publication No. 19: Oxford, Blackwell Scientific.

EUG (ed.), 1989, Milankovitch cyclicity: Terra nova, v. 1, pp. 1-479.

Garašanin, M. (ed.), 1979, La vie et l'oeuvre de Milutin Milanković 1879-1979: Conferences scientifiques, Académie Serbe des Sciences et des Arts, v. 12, Belgrade, 1982

Hays, I. D., Imbrie, I., and Shackleton, N. I., 1976, Variations in the Earth's orbit: pace-maker of the ice ages: Science, v. 194, pp. 1121-1132.

Hinnov, L. A., 2004, Astronomical signals from Pre-Cenozoic Eras, in reference No. 2 of this bibliography, pp. 51-73.

House, M. R. and Gale, A. S. (eds), 1996, Orbital forcing time scales and cyclostratigraphy: London, Geological Society, Special Publication, No. 85.

Imbrie, I. and Imbrie, K. P., 1979, Ice ages: solving the mystery: New Jersey, Enslaw Publishers.

Milankovich, M., 1920, Thèorie mathématique des phénomènes thermiques produits par la radiation Solaire: Paris, Gauthier-Villars.
Milankovich, M., 1930, Mathematische Klimalehre und astronomische Theorie der Klimaschwankungen: in Köppen-Geigersches Handbuch der Klimatologie, v. 1, Part A, Berlin.

Milankovich, M., 1938, Astronomische Mittel zur Erforschung der erdgeschichtlichen Klimate, in Geiger (ed.), Handbuch der Geophysik, v. 9, Section 7, Berlin.

Milankovich, M., 1938a, Neue Ergebnisse der astronomischen Theorie der Klimaschwankugen: Bulletin de l'Académie Royale Serbe des Sciences Mathématiques et Physiques, Series A Mathématiques et Physiques, No. 4, pp. 1-41, Belgrade.

Milankovich, M., 1941, Kanon der Erdbestrahlung und seine Anwendung auf das Eiszeitenproblem: Special Publications, v. 132, Section of Mathematics and Natural Sciences, v. 33, Belgrade, Königliche Serbische Akademie.

Milankovich, M., 1953, La part des sciences exactes dans les recherches des ages géologiques: Actes du IV-ème Congrès international du Quaternaire, v. 2, pp. 858-862, Rome (1956).

Milankovich, M., 1969, Canon of Insolation and the Ice Age Problem: Jerusalem. Israel Program for Scientific Translations.

Milanković, M., 1997, Kanon osunč avanja Zemlje i njegova primena na problem ledenih doba: Izabrana dela, knjiga 1 i 2: Zavod za udžbenike i nastavna sredstva, Beograd.

Milanković, M., 1998, Canon of Insolation and the Ice-Age Problem: Zavod za udž benike i nastavna sredstva, Belgrade (first published in German by Serbian Royal Academy, 1941: see note 14).

Milanković, M., 1995, Milutin Milanković, 1879-1958: from his autobiography with comments by his son, Vasko and a preface by André Berger: Berlin, Springer.

Mužijeviić, M., 1979, List of Milutin Milanković's works, in T. Andelić (ed.), Život i delo Milutina Milanković, a 1879-1979, pp. 179-198, Galerija Srpske akademije nauka i umetnosti, No. 36, Beograd.

Schwarzacher, W., 1993, Cyclostratigraphy and the Milankovitch theory: Developments in sedimentology, No. 52, Amsterdam, Elsevier.

\section{Aleksandar Grubic}

Faculty of Geology and Mining

Belgrade University

Djusina 7, Belgrade

Serbia

\section{Hutchison 'Young Scientist' Fund}

William Watt Hutchison, "Hutch" to his many friends around the world, was a Scots-born Canadian geologist who served Canada and the IUGS in myriad dynamic and creative ways. Most notably, he served as the IUGS Secretary General (1976-1980) at a pivotal time in its history, and as IUGS President (1984-1987). The same boundless energy, enthusiasm, skill in communications, and ability to foster teamwork that characterized his work with the IUGS also carried him to preeminent scientific administrative positions in the Canadian Government, where he served as Director General of the Geological Survey of Canada and as Assistant Deputy Minister of Earth Sciences. His distinguished career was terminated in 1987 by his untimely death at the age of 52, following a painful struggle with cancer.

One of Hutch's last wishes was to establish under IUGS auspices a memorial foundation intended to promote the professional growth of deserving, meritorious young scientists from around the world by supporting their participation in important IUGS-sponsored conferences. The first 3 beneficiaries of the Hutchison "Young Scientist" Foundation attended the 28th International Geological Congress (IGC) in Washington, D.C., in 1989.

Initially, earned interest on the funds available to the Hutchison Foundation were insufficient to sustain comparable grants every four years without seriously eroding the principal. For that reason, the IUGS made no grants from the Foundation for the 30th IGC (1996), preferring instead to strengthen the fund by allowing it to earn interest for a longer period of time and by appealing for donations from the international geologic community. Grants from the Foundation again supported deserving young scientists beginning with the 31st IGC (2000), and should continue for future Congresses. The IUGS would like to expand the resources of the Foundation to make it possible also to offer support to deserving young scientists to attend other important IUGS-sponsored scientific meetings. The Hutchison "Young Scientist" Foundation is a worthy cause that honors a fine, caring man and a distinguished, public-spirited scientist and administrator. The foundation also celebrates and promotes those things that gave Hutch the most professional satisfaction: geology, international scientific collaboration, and stimulating young minds.

The IUGS welcomes contributions to the Hutchison "Young Scientist" Foundation. Please send donations to:

Dr. Antonio Brambati

IUGS Treasurer

Dept. of Geological, Environmental and Marine Sci. (DiSGAM),

University of Trieste, 1-34127 Trieste, ITALY

Tel: +39040 558 2046; Fax: +39040558 2048

E-mail: brambati@univ.trieste.it

Checks in US dollars or Visa/Mastercard (please include account number and expiration date) are preferred in order to avoid the high cost of currency conversions. Residents of the U.S.A. are reminded that charitable gifts of this nature are tax deductible. 